\title{
Beta Cell Function: A Useful Measure of Insulin Resistance in Adolescent with Polycystic Ovarian Disease
}

\author{
Reema Irum, ${ }^{1}$ Ghazala Qureshi, ${ }^{2}$ Alia Dilawar, ${ }^{3}$ Rukhshan Khurshid, ${ }^{4}$ Shirin Khawar $^{5}$
}

\begin{abstract}
Polycystic ovarian syndrome (PCOS) is the universal endocrine disarray in premenopausal women, These women are prone to insulin resistance as well as altered beta cell function. Study was designed to find out the relationship of insulin resistance and beta-cell function in adolescent with PCOS.
\end{abstract}

Material and Methods: Study included 50 female patients, aged range 16-20 years from Obstetrics and Gynaecology department in Lahore. All subjects were already diagnosed and documented as patients of polycystic ovarian syndrome on the basis of pelvic ultrasonic findings. Level of serum insulin was estimated by ELISA technique using standard kit. Level of fasting glucose was estimated by glucose oxidase

\footnotetext{
${ }^{1}$ Department of Physiology

Fatima Jinnah Medical University, Lahore

${ }^{2}$ Department of Physiology

Sharif Medical and Dental College, Lahore

${ }^{3}$ Department of Pathology

Akhtar Saeed Medical and Dental College, Lahore

${ }^{4}$ Department of Biochemistry

Fatima Jinnah Medical University, Lahore

${ }^{5}$ Department of Physiology

Fatima Jinnah Medical University, Lahore
}

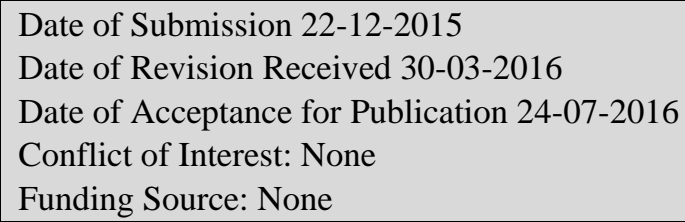

\section{Contribution}

All Authors have contributed in Study Design, Data Collection, Data Analysis, Data Interpretation, Manuscript Writing and Approval. method. The value of insulin resistance, glucose: insulin ratio and Beta cell function were calculated.

Results: Mean age of subjects with PCOS and control was 18.9 and 18.6 year respectively. Fasting glucose of PCOS subject was non-significantly decreased when compared to their controls. Serum level of insulin was significantly $(\mathrm{P}<0.001)$ increased in patients compared to their controls. Glucose insulin (GIR) ratio was significantly decreased $(\mathrm{P}<0.001)$ when compared to their controls. Insulin resistance was non-significantly increased in subjects as compared to their controls. Increased function of beta cell was found in PCOS subjects as compared to their controls. The Pearson's correlation showed a positive significant correlation between HOMA - IR and fasting insulin. A significant correlation was observed between level of insulin and insulin resistance. Weak correlation was observed between level of insulin and beta cell function.

Conclusion: It is the concluded that function of beta cell failure to compensate insulin resistance increases the risk of diabetes in adolescent with PCOS. More research is needed to define the degree of beta cell effect.

Key Words: PCOS, insulin, beta cell function, HOMA - IR.

\section{Introduction}

Polycystic ovarian syndrome (PCOS) is one of the most-widespread endocrine disarray in premenopausal women with $4-12 \%$ prevalence rate. ${ }^{1}$ PCOS is characterized by menstrual irregularity, infertility, an ovulation, hyperandrogenism, and insulin resistance. ${ }^{2}$

Insulin upholds glucose homeostasis in association with both glucose uptake gluconeogenesis states. 
Moreover, other roles of insulin are related to renal, neural and cardiovascular function. This showed the association of insulin resistance with risk of hypertension, heart problems and nephropathy etc. ${ }^{3}$ Insulin signaling by different metabolites and crosstalk with some other signaling pathways directs to insulin resistance. Increase insulin level also increased insulin resistance. Insulin resistance is typified by a decreased cell or tissue ability to counter the level of insulin. According to studies up to $90 \%$ of PCOS women have insulin resistance. ${ }^{4,1}$

Changes in release of insulin due to changes in insulin sensitivity cause the changes in the secretory capacity of the beta cell. ${ }^{5,6}$ In response to increasing insulin resistance, beta cell secretes more insulin in normal physiological state. However in susceptible individuals beta-cell function begins to decline and in case of severe but stable insulin resistance leads to hyperglycemia which may results an increase in demand for insulin. There is also a change in function of beta cells causing hyperplasia of beta cells. The malfunction of the beta cell to insulin resistance is responsible for increase in the risk of type 2 diabetes in women with PCOS. ${ }^{5}$

Pathogenesis of beta-cell failure is based on increased influx of glucose and fatty acids due to increased response. The increase in metabolism of glucose and fatty acids may causes insulin resistance and disruption in the function of beta cell. ${ }^{7,8}$ It is postulated that cells of the body shows resistance to insulin effect as the insulin receptors become less responsive to insulin resulting in an increase release of insulin from beta cells and cause hyperinsulinemia ${ }^{9}$. Insulin resistance can be assessed with fasting insulin, fasting glucose: insulin $(\mathrm{G} / \mathrm{I})$ ratio, beta cell function and $\mathrm{HOMA}_{\mathrm{IR}}{ }^{10,11}$

As the abnormalities in insulin level are poorly detected by simple determination of either glucose or insulin. There is a need to find out not only the insulin resistance but also study the beta cell function in PCOS.

\section{Patients and Method}

Study included 50 female patients from Obstetrics and Gynaecology Department in Lahore. Females between the ages $16-20$ year were registered. All subjects were at their reproductive age and already diagnosed and documented as patients of polycystic ovarian syndrome on the basis of pelvic ultrasonic findings. Subjects with hyperthyroidism, hypothyroidism, con- genital adrenal hyperplasia and diabetes mellitus were not included in the study. Normal subjects with no disease were taken as controls. Letter of consent was taken from each subject. This study has been endorsed by Ethical Committee.

About $5.00 \mathrm{ml}$ blood was drawn after overnight fasting of both patients and normal subjects. For estimation of blood glucose, about $2.00 \mathrm{ml}$ of blood was taken in anticoagulant coated tube and estimated by glucose oxidase method using standard kit of Merck. Remaining $3.00 \mathrm{ml}$ of blood was allowed to clot and centrifuge. Serum was separated and used for estimation of insulin level using ELISA technique kit Human insulin Norvex (cat no: KAQ1251). The value of insulin resistance and glucose insulin ratio were calculated using the formula.

Insulin resistance $=[$ fasting insulin $(\mathrm{uU} / \mathrm{ml}) \times$ fasting glucose $(\mathrm{mg} / \mathrm{dl}) / 405]$.

Glucose:insulin ratio $=[$ glucose $(\mathrm{mg} / \mathrm{dl}) /$ insulin $(\mathrm{uU} / \mathrm{ml})] .{ }^{12}$

Beta cell function was found using formula of Homa $-\% \mathrm{~B}_{1}=[$ Fasting insulin/fasting glucose $\times$ $0.0555]-3.5 .^{13}$

Data is shown as means $\pm \mathrm{SD}$. Variations in the parameters of patients were compared by student t-test using SPSS 16. $\mathrm{P}$ value $<0.05$ was taken as statistically significant. Correlation between serum insulin, insulin resistance and beta cell function was find by Pearson's correlation coefficient.

\section{Results}

Age and Biochemical characteristics of adolescent are tabulated. Mean age of subjects with PCOS and of control was $18.9 \pm 1.14$ and $18.6 \pm 1.12$ year respectively. Fasting glucose of PCOS subject was non-significantly decreased when compared to normal subjects. Serum insulin level was significantly increased $(\mathrm{P}<0.001)$ in patients as compared normal subjects. Glucose insulin (GIR) ratio was decreased significantly $(\mathrm{P}<0.001)$ when compared with the ratio of normal subjects. Insulin resistance was non-significantly increased in subjects compared to the insulin resistance of normal subjects. Beta cell function was increased in subjects with PCOS compared to beta cell function.

The Pearson's correlation showed that there was significant positive correlation between HOMA - IR and fasting insulin $(\mathrm{r}=0.5828)$. A weak negative 
correlation $(\mathrm{r}=-0.335)$ was noted between level of insulin and beta cell function (Table 2).

\section{Discussion}

Polycystic ovary syndrome accounts for the vast majority of an ovulatory symptoms and hyperandrogenism in women. Chief complaint of adolescent girl was hirsutism, menstrual irregularity, treatment-resistant acne as well as obesity may be a signal of $\mathrm{PCOS}^{14}$.

Mean age of subjects with PCOS and of control was $18.9 \pm 1.14$ and $18.6 \pm 1.12$ year respectively. However a study found that average age was of women with PCOS was $26.3 \pm 5.4$ years ranged 17 to 36 years. $^{14}$

Fasting glucose of subject with PCOS was non-significantly decreased when compared to glucose level of normal subjects. Our study is in line with a study showed that similar levels of glucose in subject with PCOS. ${ }^{15}$ It is stated that glucose levels are not a predictor of insulin resistance, however it may be related with dyslipidemia and coronary artery disease (CAD). ${ }^{16}$

Level of serum insulin was increased in subjects compared to the level of insulin in normal subject and showed a highly significant difference $(\mathrm{t}=2.67, \mathrm{P}<$ $0.001)$. An increased level of fasting insulin was also reported by a group of workers. ${ }^{15,17}$ Number of studies have shown that there is a imperfection in glucosestimulated insulin secretion. ${ }^{18,19}$ However according to some studies patients with PCOS have an increased insulin response, maybe for compensation of insulin resistance. $^{20,21}$ Nevertheless some researchers have reported normal insulin secretion in patients with PC$\mathrm{OS}^{22,23}$

The Pearson's correlation was shown that there was a significant positive correlation between insulin resistance and fasting insulin $(r=0.5828)$. However, number of studies does not found any correlation between insulin secretion and insulin resistance. Studies reported that although the insulin response may be increased, it may not be suitably increased to relate with the degree of insulin resistance. ${ }^{24}$

Glucose insulin ratio (GIR) was decreased significantly $(\mathrm{t}=2.81, \mathrm{P}<0.001)$ in subjects when compared to their controls. According to a study the fasting glucose/insulin ratio is a valuable screening test for insulin resistance in the age of adolescent. ${ }^{25}$ Another study also found that GIR was found to be the highly discriminative of glucose disposal rate, upright degree of insulin sensitivity and has highly sensitive for detection of insulin resistance in PCOS patient. ${ }^{26}$ It is found by a group of workers that GIR are sensitive measure of insulin resistance in patients with PCOS. They concluded that these are the patients who need insulin lowering agents and not ovulation induction therapy alone. $^{17}$

Insulin resistance was non-significantly increased in subjects as compared to their controls. It is reported that mitochondrial dysfunction may be responsible for metabolic disturbances related to insulin - resistant states. ${ }^{27}$ A study found that due to insulin resistance, an increase secretion of insulin from $\beta$-cell of pancreas in a compensatory mode. ${ }^{18}$ Another study stated that a small number of PCOS women with insulin resistance 
may develop diabetes. This suggests that such patients may also have primary defects in insulin secretion. ${ }^{2}$ Additionally it is reported that both disturbed beta cell function and defect in insulin levels are related with impaired glucose metabolism. ${ }^{28}$

Present study found an increased function of beta cell in PCOS adolescent compared to normal subjects. It is reported that due to the increased function of beta cell, secretion of insulin decreased progressively so that these individuals may have a high risk of developing diabetes. ${ }^{5}$ According to a study insulin response to glucose is not linked with a change of insulin sensitivity. Thus, there may be a defect in $\beta$-cell women with PCOS. ${ }^{24}$

According to our study significant correlation was observed between fasting insulin level and insulin resistance. Our study is in line with that of Laasko who found a significant correlation between fasting insulin and insulin resistance. Study concluded that the increases in fasting insulin levels appear to be compensatory attempts to overcome the resistance to glucose uptake. ${ }^{27}$

We also observed a weak correlation between level of serum insulin and beta cell function. According to a study, $\beta$-cell function changes with variation in insulin sensitivity. Study also found that the relationship is a hyperbola i.e. with increase insulin sensitivity there is small alteration in insulin levels and responses, whereas a decrease in insulin sensitivity causes a big change in level of insulin and responses ${ }^{29}$. Another study concluded that conserving beta cell function, signaling of insulin in beta cells and signaling of insulin in the glucose beneficiary tissues uphold glucose homeostasis. ${ }^{30}$

\section{Conclusion}

It is therefore concluded that function of beta cell failure to reimburse insulin resistance increases the diabetes risk in adolescent with PCOS. More research is needed to define the degree of beta cell effect.

\section{References}

1. Dunaif A, Thomas A. Current concepts in the polycystic ovary syndrome. Annu Rev Med. 2001; 52: 401419.

2. Ehrmann DA, Kasza K, Azziz R, Legro RS, Ghazzi MN. PCOS/Troglitazone Study Group. Effects of race and family history of type 2 diabetes on metabolic sta- tus of women with polycystic ovary syndrome. J Clin Endocrinol Metab. 2005; 90: 66-71.

3. Kalofoutis C, Piperi C, Kalofoutis A, Harris F, Phoenix D, Singh J. Type II diabetes mellitus and cardiovascular risk factors: Current therapeutic approaches. Exp Clin Cardiol. 2007; 12 (1): 17-28.

4. Dunaif A. Insulin action in the polycystic ovary syndrome. Endocrinol Metab Clin North Am. 1999; 28: 341359.

5. Kahn SE, Prigeon R L, McCulloch D K, Boyko E J, Bergman RN, Schwartz MW. Quantification of the relationship between insulin sensitivity and B-cell function in human subjects. Evidence for a hyperbolic function. Diabetes, 1993; 42: 1663-1672.

6. Beard, JC, Ward WK, Halter JB, Wallum BJ \& Porte D. Relationship of islet function to insulin action in human obesity. J. Clin. Endocrinol. Metab. 1987; 65: $59-64$.

7. Elbein S C, Wegner K and Kahn SE. Reduced b-cell compensation to the insulin resistance associated with obesity in members of Caucasian familial type 2 diabetic kindreds. Diabetic Care, 2000; 23: 221-227.

8. Cavaghan MK, Ehrmann DA, Byrne MM. and Polonsky KS. Treatment with the oral antidiabetic agent troglitazone improves beta cell responses to glucose in subjects with impaired glucose tolerance. J. Clin. Investig. 1997; 100: $530-537$.

9. Shanik MH, Yuping X, Skrha J, Danker R, Zick Y, Roth J. Insulin Resistance and Hyperinsulinemia "Diabetes Care, 2008; 31 (2): s262-s268.

10. Kauffman RP, Baker VM, Dimarino P, Gimpel T, Castracane VD. Polycystic ovarian syndrome and insulin resistance in white and Mexican American women: a comparison of two distinct populations.Am J Obstet Gynecol. 2002; 187: 1362-1369.

11. Wu XK, Zhou SY, Liu JX, Pollanen P, Sallinen K, Makinen M, Erkkola R. Selective ovary resistance to insulin signaling in women with polycystic ovary syndrome. Fertil Steril. 2003; 80: 954-965.

12. Salgado AL, Carvalho LD, Oliveira AC, Santos VN, Vieira JG, Parise ER. Insulin resistance index (HOMAIR) in the differentiation of patients with non-alcoholic fatty liver disease and healthy individuals. Arq Gastroenterol. 2010 Apr - Jun; 47 (2): 165-9.

13. Niemczyk S. Giers K, Jasik M, Bartoszewicz Z, Romejko - Ciepielewska K. Homeostatic model assessment indices in evaluation of insulin resistance and sec-retion in hemodialysis patients. Med Sci Monit. 2013; 19: 592-598.

14. Frank S. Polycystic ovary syndrome. N Engle J Med. 1995; 333: 853-861.

15. Liu J, Li YB, Shao H, Li YX, Yuan YH, Xiao YB, Weng JP. Evaluation of islet beta cell function in subjects with normal glucose tolerance, impaired glucose regulation, and type 2 diabetes mellitus. Zhonghua Yi XueZaZhi. 2007 May 15; 87 (18): 1252-5. 
16. Karakas SE, Kim K, Duleba AJ. Determinants of impaired fasting glucose versus glucose intolerance in polycystic ovary syndrome. Diabetes Care, 2010; 33: 887893.

17. Sultana K, Shamsi A and Amir S. Fasting Glucose to Insulin Ratio in Obese and None Obese Women with Polycystic Ovarian Syndrome. Pak J Med Health Sci. 2011; 5 (2): 338-40.

18. Dunaif A, Finegood DT. Beta - cell dysfunction independent of obesity and glucose intolerance in the polycystic ovary syndrome. J Clin Endocrinol Metab. 1996; 81: 942-947.

19. Arslanian SA, Lewy VD, Danadian K. Glucose intolerance in obese adolescents with polycystic ovary syndrome: roles of insulin resistance and beta-cell dysfunction and risk of cardiovascular disease. J Clin Endocrinol Metab. 2001; 86: 66-71.

20. Morin - Papunen LC, Vauhkonen I, Koivunen RM, Ruokonen A, Tapanainen JS. Insulin sensitivity, insulin secretion, and metabolic and hormonal parameters in healthy women and women with polycystic ovarian syndrome. Hum Reprod. 2000; 15: 1266-1274.

21. Vrbíková J, Grimmichová T, Dvoráková K, Hill M, Stanická S, Vondra K. Family history of diabetes mellitus determines insulin sensitivity and beta cell function in polycystic ovary syndrome. Physiol Res. 2008; 57: 547-553.

22. Gennarelli G, Rovei V, Novi RF. Preserved insulin sensitivity and beta - cell activity, but decreased glucose effectiveness in normal - weight women with the polycystic ovary syndrome. J Clin Endocrinol Metab. 2005; 90: 3381-3386.
23. Svendsen PF, Nilas L, Nørgaard K, Jensen JE, Madsbad S. Obesity, body composition and metabolic disturbances in polycystic ovary syndrome. Hum Reprod. 2008; 23: 2113-2121.

24. Messer C, Boston R, Leroith D, Geer E, Miller JD, Messer M, Futterweit W. Pancreatic $\beta$-cell dysfunction in poly cystic ovary syndrome: The role of Metformin.t Endocr Pract. 2012; 18 (5): 685-693.

25. Vuguin P, Saenger P, Dimartino - Nardi J. Fasting glucose insulin ratio: a useful measure of insulin resistance in girls with premature adrenarche. J Clin Endocrinol Metab. 2001 Oct; 86 (10): 4618-21.

26. Ducluzeau PH, Cousin P, Malvosin E, Bornet H, Vidal H, Laville M, Pugeat M. Glucose - to - Insulin Ratio Rather than Sex HormoneBinding Globulin and Adiponectin Levels Is the Best Predictor of Insulin Resistance in Nonobese Women with Polycystic Ovary Syndrome. The J Clin Endoc and Meta. 2003; 88 (8): 3626-3631.

27. Han XY, Ji LN, Zhou XH. Insulin sensitivity and beta function in the first - degree relatives of type 2 diabetic patients. Zhonghua Yi XueZaZhi. 2004 Nov. 2; 84 (21): 1777-80.

28. Laakso M. How Good a Marker Is Insulin Level for Insulin Resistance? Am. J. Epidemiol. (1993) 137 (9): 959-965.

29. Kahn SE. The relative contributions of insulin resistance and beta-cell dysfunction to the pathophysiology of Type 2 diabetes. Diabetologia. 2003 Jan; 46 (1): 319.

30. Cerf ME. Beta Cell Dysfunction and Insulin Resistance. Front Endocrinol (Lausanne), 2013; 4: 37. 